\title{
Phonological codes and functional spelling units: Reality and implications
}

\author{
LINDA PRING \\ MRC Developmental Psychology Unit, Drayton House, Gordon Street, London WCIH OAN, England
}

\begin{abstract}
The grapheme-to-phoneme correspondence procedure for generating nonlexical phonological codes comprises two stages. The first, a parsing procedure, divides a letter string into functional spelling units (FSUs), each unit corresponding to a single phoneme. The second stage assigns the appropriate phoneme to the spelling units according to predictable or regular spelling-tosound patterns. In a lexical decision task, it was found that disrupting the spelling units, by alternating the case of letters within the units (e.g., ChuRCH) caused the pseudohomophone effect to be abolished. In contrast, disrupting the visual appearance of the letter strings but leaving the FSUs intact (e.g., $\mathrm{CHurCH}$ ) allowed the pseudohomophone effect to emerge. The results are considered in the light of the recent "activation and synthesis" model proposed by Glushko (1979).
\end{abstract}

There are several models of how print might be translated into sound (e.g., Coltheart, 1979; Glushko, 1979; Marcel, 1980; Morton \& Patterson, 1980). Among these there appear to be two critical areas of controversy. The first is whether there exists a nonlexical route in reading. This route would involve a procedure capable of converting the graphemic representation of a printed letter string into a phonological representation on the basis of rules. One proposal has emphasized the role of a grapheme-to-phoneme correspondence procedure (Baron \& Strawson, 1976; Coltheart, 1979; Midgley-West, 1979). This procedure might be responsible for converting a graphemic code into a phonological one by using predictable spelling-to-sound patterns that exist in the written and spoken language. Essentially, there would be two operations to this transformation process. First, a parsing procedure would divide the letter string into letter units, each unit corresponding to a single phoneme. Thus, CHURCH could be divided into three functional spelling units, $\mathrm{CH}, \mathrm{UR}$, and $\mathrm{CH}$, corresponding to three single phonemes, $/ \mathrm{t} \int /, / 3: /$, and $/ \mathrm{t} \int /$. The second operation, the phoneme assignment stage, would simply assign one phoneme to each unit according to regular or predictable spelling-to-sound patterns (Venezky, 1970; Wijk, 1966). Evidence in support of this proposal has come from several sources (Baron \& Strawson, 1976; Coltheart, Besner, Jonasson, \& Davelaar, 1979; Gough \& Cosky, 1977; MidgleyWest, 1979; Stanovich \& Bauer, 1978) which imply that, when a nonlexical phonological code is used in reading tasks, then that group of words containing regular or predictable spelling-to-sound patterns is dealt with differently from that group having irregu-

This work was undertaken at Birkbeck College, University of London, and was supported by an SSRC studentship. lar or unpredictable patterns. It is hypothesized that the latter group of words cannot gain "correct" phonological representations via the grapheme-phoneme correspondence procedure.

These irregular words, such as YACHT or LOVE (the final e normally lengthens the preceding vowel), cannot be represented independently of the internal lexicon. The lexicon is understood to store word information, including spelling and pronunciation, and it would be from here that phonological representations of irregular words (and regular ones) could be found.

Baron (1979) has pointed out that rules can be used to generate phonological codes without necessarily representing them as grapheme-phoneme correspondences. He proposes that readers can use large-unit rules as well as small-unit rules. The large units, such as AVE, ATE, OO, can be stored in memory, each with its respective pronunciation. The small-unit rules would be grapheme-phoneme correspondences (GPCs). This suggestion serves to broaden the basis upon which the nonlexical route could handle information, and the phonological information that it might provide could be useful in the reading processsay, for example, in an analogy procedure. Thus, Baron proposes a nonlexical route that could, in conjunction with lexical analogy procedures, be responsible for converting print to sound.

The second area of dispute is virtually a corollary of the first and is concerned with whether or not direct visual access to the internal lexicon proceeds on the basis of whole words or whether smaller units (e.g., AVE or EEN) can be used. Thus, whereas the first issue is concerned primarily with the existence of a nonlexical phonological mechanism responsible for generating phonological codes. The second point concentrates not on rule generation but instead refers to the presence or absence of not only word units, 
but also smaller, multiletter units, in the internal lexicon. It might be noted that Coltheart (1979) has argued persuasively-against the use of a syllabary or phonological lexicon in which parts of words and their phonological representations are stored. If smaller units are involved in lexical access, then clearly some kind of parsing process must differentiate which units to use (see Marcel, 1980, for a discussion of this issue). Furthermore, analogy procedures such as those proposed by Baron (1979) might provide phonological codes for regular or irregular words as well as nonwords such as SLINT or BROBE. Several authors have put forward how such lexical procedures might work, either dependently or independently of a grapheme-phoneme correspondence procedure (Baron, 1977a, 1977b, 1979; Glushko, 1979; Marcel, 1980; Shallice \& Warrington, 1980). Baron (1979), for example, suggests that large units could be used as part of an analogy procedure with readers selecting words that differ only in initial consonant or consonant cluster, retrieving the representations for large units (i.e., multiletter units), and using grapheme-phoneme correspondences to provide the initial consonant(s).

However, recently Bauer and Stanovich (1980) and Glushko (1979) have reported evidence that, they would assert, diminishes the possible role of a grapheme-phoneme correspondence procedure in reading. Instead, an alternative proposal has been put forward, an "activation and synthesis" model. This model, described by Glushko (1979), is based on the understanding that visually presented letter strings can be pronounced on the basis of several alternative sources of information, activated in parallel, and synthesized to produce an articulatory program. The fundamental notion is that when readers are presented with a word or nonword to pronounce, several candidate lexical entries are activated that share similar orthographic features. Glushko suggests that there are procedures that determine how to modify the activated information in order to synthesize the appropriate articulatory code. So that, for example, VATE might be pronounced on the basis of specific rules using multiletter correspondence patterns (i.e., -ATE pattern) or by analogy with other words (i.e., GATE or DATE). In Glushko's view, then, it seems that the use of nonlexical information and the utilization of lexical analogy procedures are not mutually exclusive. Instead, pronunciation can proceed from the information that the routes make available, either separately or in parallel. Yet, the procedures that determine how to use these several sources of information are not described. Baron (1977a, 1977b, 1979) does describe in more detail such an analogy procedure, but the emphasis is on gaining representations for legal nonwords. Nevertheless, one prediction that can be made following the "activation and synthe- sis" model is that some words or nonwords may lead to an activation of a consistent field of lexical entries, providing consistent (shared) phonological features, whereas others may lead to the activation of an INCONSISTENT field of lexical entries. For example, with the presentation of a nonword such as HEAF, a regular word such as LEAF might be activated, but also an irregular word such as DEAF. In such a situation, the stored phonological codes provide inconsistent information, and difficulties will arise in the synthesis process.

Now, the proponents of the grapheme-phoneme correspondence procedure would normally predict that all nonwords are pronounced without reference to the internal lexicon and codes stored there, but rather on the basis of regular, nonlexical graphemephoneme correspondences. Yet, Glushko (1979) has reported that both words and nonwords can be divided into two groups, depending on whether or not they would activate consistent or inconsistent fields in the lexicon and, furthermore, that the "consistent field" letter strings are named significantly faster and with fewer errors than the "inconsistent field" letter strings. The implication is that nonlexical phonological coding has little influence on the pronunciation of letter strings relative to lexical activation. However, one way that might distinguish between the grapheme-phoneme correspondence procedure and the activation and synthesis model is to determine whether functional spelling units have any psychological reality. If they do and they appear to be involved in the process responsible for generating phonological codes, it is hard to see how Glushko could account for them within his model. The assumption of FSUs emphasizes the presence of nonlexical phonological coding, whereas the activation and synthesis model stresses lexical analogies in getting from print to sound.

The aim of the experiment reported here is to investigate the effect of disrupting the FSUs within a letter string. The visual appearance of a letter string can be disrupted by alternating the case of letters within that string (e.g., pInT or GrAtE). It has been argued that disrupting the visual pattern of a word in this way may allow the indirect, phonological lexical access route to gain an advantage over the direct, visual route (Baron \& Strawson, 1976). Alternatively, it has been suggested that case alternation simply slows down the initial graphemic encoding procedure and has no effect on subsequent processing (Coltheart et al., 1979). Here the interest is with FSUs (NB: each FSU maps onto one phoneme), and it is possible to use case alternation in a letter string while leaving the FSUs intact or to use case alternation to disrupt the FSUs. For example, in $\mathrm{CHurCH}$ the case is alternated between the FSUs, therefore leaving them intact but disrupting the appearance of the word, whereas 
in ChuRCh the case alternation is within the FSUs, therefore both disrupting the appearance of the word and disrupting the FSUs.

To investigate whether the intact/disrupted FSUs variable is important in reading, a lexical decision experiment was carried out, including words, pseudohomophones (e.g., BLOO or CHERCH), and nonwords (e.g., SLINT or BRABE). Under normal circumstances, it has been found that the NO response to pseudohomophones is significantly slower than the NO response to legal nonwords (Coltheart, Davelaar, Jonasson, \& Besner, 1977; Rubenstein, Lewis, \& Rubenstein, 1971). It has been argued that in such a lexical decision task the nonlexical phonological code constructed from a pseudohomophone serves to activate its homophonic word equivalent in the internal lexicon (Rubenstein et al., 1971), and this acts to limit the confidence with which subjects can reject pseudohomophones relative to nonword items (Coltheart, 1978). Two points emerge: If disrupting the visual appearance of letter strings gives an advantage to the indirect phonological route, then we would expect a pseudohomophone effect to emerge in both an intact FSU and a disrupted FSU condition, since in both these cases the visual appearance of the letter strings is disrupted. Also, if it is true that phonological codes may be difficult to generate from stimuli with disrupted FSUs because of the problems caused for the grapheme-phoneme correspondence procedure, then we might expect the pseudohomophone effect to be abolished under the disrupted FSU condition, but to emerge in the intact FSU condition. In summary, if disrupting the visual appearance of letter strings prevents a nonlexical phonological code from being generated, then in the following experiment a pseudohomophone effect will not be apparent. If, on the other hand, a pseudohomophone is apparent in both the FSU-intact condition (i.e., $\mathrm{CHurCH}$ ) and the FSU-disrupted condition (i.e., ChuRCH), then not only is visual appearance without an effect, but, more importantly, we have not found support for the psychological reality of FSUs. That is because their disruption proved an ineffective form of interference. Finally, if a pseudohomophone effect should emerge in the FSU-intact condition but not in the FSU-disrupted condition, then we would have found some evidence for the involvement of FSUs, and thus a GPC procedure, in the generation of phonological codes. In addition, if this result should pertain, it would indicate that disrupting the visual appearance of letter strings per se does not affect the mode of subsequent processing.

\section{METHOD}

\section{Subjects}

Ten male and 10 female subjects participated in the experiment. They were all undergraduates at Birkbeck College and were between 19 and 25 years of age.

\section{Stimulus Materials}

A complete list of the stimuli used in this experiment is provided in the appendix. These included 76 English words, 38 pseudohomophones such as BRANE or GRENE, and 38 nonwords such as BRENE or CRENE. The nonwords were constructed by changing just one letter in one position of the pseudohomophones; thus, they acted as closely matched, pairwise controls.

Each stimulus was presented in a mixture of upper and lowercase letters, but it was possible to present the stimulus either with its functional spelling units intact (e.g., BLoo or PLoo) or with the units disrupted (e.g., GraIT or BraIT). All the stimuli began with an uppercase letter.

\section{Apparatus}

Stimuli were presented to the subjects on four Advance 05250 cathode-ray oscilloscopes (CRO), which were slaved to a PDP-11 computer. In front of each CRO were two response buttons that the subject held, one in each hand, and used by depressing a button under the thumb. The computer recorded the response times.

\section{Design}

Each subject saw all 152 stimuli in a randomized order. Each experimental session used a difierent random order of presentation. There were 21 practice trials before the experimental trials.

Half of the stimuli in each of the three categories (words, pseudohomophones, and nonwords) were presented with their FSUs intact, and the other half of the stimuli were presented with their FSUs disrupted. For each experimental session, the stimuli were selected randomily with respect to the type of visual distortion (intact or disrupted) they were to represent, with the proviso that any given pseudohomophone and its matched control nonword would be presented with the same type of visual distortion.

Therefore, each subject could eventually contribute six mean scores: intact FSUs-words, pseudohomophones, and nonwords; disrupted FSUs - words, pseudohomophones, and nonwords.

An experimental trial consisted of displaying a fixation point for $500 \mathrm{msec}$. This was immediately followed by the presentation of the stimulus, which remained on the screen for up to $2 \mathrm{sec}$ or until a response was made. The interstimulus interval was $1,500 \mathrm{msec}$.

\section{Procedure}

Subjects were given the following set of instructions: "In this experiment your task is simply to decide whether the letter-string that appears on the screen in front of you is an English word or a nonword. A nonword is a letter-string that could be a word because it can be easily pronounced but it does not mean anything. So, for example, CHERCH and SLINT are nonwords. If the letter-string is a word press the black button as quickly as possible. If the letter-string is a nonword press the red button as quickly as possible. Keep your errors to a minimum, but if you do make a mistake just carry on with the next trial, don't worry."

The subject responded YES with the dominant hand and NO with the other hand.

\section{RESULTS}

Incorrect responses were disregarded. The mean reaction times, standard deviations, and error rates across subjects are provided in Table 1. The mean reaction times and standard deviations averaged across the three types of printed letter strings (i.e., word data) are not presented since the results of the word analyses concurred with the subject analyses.

A repeated measures analysis of variance was carried out on the data with two within-subject variables, each with two levels. The first within-subject 
Table 1

Mean Reaction Times (in Milliseconds), Standard Deviations, and Error Rates (in Percentages) in the Lexical Decision Experiment

\begin{tabular}{|c|c|c|c|c|c|c|c|c|c|}
\hline \multirow{4}{*}{$\begin{array}{c}\text { Functional Spelling } \\
\text { Units }\end{array}$} & \multicolumn{9}{|c|}{ Type of Letter String } \\
\hline & \multicolumn{3}{|c|}{ Word } & \multicolumn{3}{|c|}{ Pseudohomophone } & \multicolumn{3}{|c|}{ Nonword } \\
\hline & \multicolumn{2}{|c|}{ Reaction Time } & \multirow{2}{*}{$\begin{array}{c}\text { Percent } \\
\text { Error }\end{array}$} & \multicolumn{2}{|c|}{ Reaction Time } & \multirow{2}{*}{$\begin{array}{c}\text { Percent } \\
\text { Error } \\
\end{array}$} & \multicolumn{2}{|c|}{ Reaction Time } & \multirow{2}{*}{$\begin{array}{l}\text { Percent } \\
\text { Error }\end{array}$} \\
\hline & Mean & SD & & Mean & SD & & Mean & $\mathrm{SD}$ & \\
\hline Intact & 569 & 83 & 2.7 & 717 & 127 & 2.3 & 673 & 109 & 1.0 \\
\hline Disrupted & 604 & 91 & 4.4 & 703 & 124 & 1.8 & 707 & 122 & 1.2 \\
\hline
\end{tabular}

variable was visual appearance (intact and disrupted functional spelling units), and the second variable was the type of letter string (legal nonwords and pseudohomophones). A summary table of that analysis is provided in Table 2 .

The main feature of the results of the analysis presented in Table 2 is the significant interaction $(p<.02)$ between visual appearance (i.e., intact and disrupted FSUs) and type of letter string (i.e., pseudohomophones and nonwords). This suggests that pseudohomophones take significantly longer to reject than do the other nonwords (the pseudohomophone effect) when the stimuli are presented with their FSUs intact. No such differences between pseudohomophones and the nonwords exists when the stimuli have their FSUs disrupted $[\mathrm{t}(19)=.332$, n.s.]. The visual appearance of the stimuli as a main effect was not significant, and overall responses to pseudohomophones were slower than responses to the nonwords $(\mathrm{p}<.0001)$.

A related $t$ test also revealed that lexical decisions in response to words presented with their functional spelling units intact were significantly faster than to words with the spelling units disrupted $[t(19)=8.332$, $\mathrm{p}<.001]$.

The error data followed the same pattern of results as the reaction-time data; two related t tests revealed that significantly more errors were made with pseudohomophones than nonwords when the stimuli were presented with the spelling units intact $[\mathrm{t}(19)=4.212$, $\mathrm{p}<.001]$, but no significant difference was found between errors made to pseudohomophones and nonwords when the functional spelling units in the stimuli were disrupted $[\mathrm{t}(19)=.842, \mathrm{n} . \mathrm{s}$.$] .$

Table 2

Summary Table of ANOVA of the Nonword Data

\begin{tabular}{lrrr}
\multicolumn{1}{c}{ Source } & df & MS & \multicolumn{1}{c}{ F } \\
\hline A & 1 & 1930.61 & 1.2477 \\
A by Subjects & 19 & 1574.38 & \\
B & 1 & 7860.61 & $15.9595 \dagger$ \\
B by Subjects & 19 & 492.53 & \\
AB & 1 & 11410.31 & $6.7333^{*}$ \\
AB by Subjects & 19 & 1693.13 & \\
\hline
\end{tabular}

Note $-A=$ visual appearance; $B=$ type of letter string.

$*_{p}<.02 . \quad t_{p}<.001$.

\section{DISCUSSION}

In this experiment, it is clear that the pseudohomophone effect emerges in a lexical decision task, even when the stimuli are disrupted in terms of the visual appearance, as long as the functional spelling units within the items remain intact. If, in contrast, the functional spelling units within the items are disrupted, then no phonological effect emerges: the pseudohomophone effect is abolished.

Clearly, disrupting the visual appearance of letter strings alone does not give an advantage to the indirect phonological route, since no phonological effect emerged in the condition in which the FSUs as well as the visual appearance of letter strings were disrupted. It appears that a critical variable is not the visual appearance per se but whether or not the FSUs within the letter strings are disrupted.

One suggestion that can be offered to account for this result is that functional spelling units are involved in the construction of a nonlexical phonological code. Disrupting the units serves to slow down the construction of the phonological code. The result is that the processes responsible for rejecting the nonword stimuli in the lexical decision task now treat pseudohomophones and nonwords alike. Nonlexical phonological information fails to be supplied to the internal lexicon, and the pseudohomophone effect therefore fails to emerge.

Evidence has been presented for the psychological reality of functional spelling units. It is hard to see how this result can be easily incorporated into the activation and synthesis model, since that model relies extensively on lexical phonology, and no theoretical or experimental evidence has revealed any correlation between FSUs and the internal lexicon. At the present time, the model has not been fully elaborated, and it is true that Baron (1979) does describe a procedure similar to that described by Glushko, but with more emphasis on grapheme-phoneme correspondences. It should be noted that in pronouncing "irregular," "inconsistent" nonwords (Glushko, 1979, Experiment 2), subjects produced regular pronunciations (or those predicted by the use of graphemephoneme correspondences) $91,3 \%$ of the time. It is not clear, then, why a reader should pronounce HEAF 
by analogy with LEAF and not DEAF, but this seems to be what occurs. This adherence to regularity lends some support to Baron in implying that nonlexical rules cannot be excluded as a major component in pronunciation, as Glushko seems to suggest. This is because the regular pronunciations are, by definition, those predicted by GPCs.

In the introduction, two controversies about the mechanisms responsible for generating a phonological representation from print were outlined. The first was whether or not the phonological representation of units smaller than whole words are accessible from the internal lexicon. If such units could be easily retrievable, then it would be the case that a nonlexical, phonological route would be largely superfluous. The possible existence, however, of such a phonological route (perhaps making use of a GPC procedure) was the basis of the second controversy raised earlier. It was to this issue that the present experiment was addressed. The results demonstrated that FSUs played a significant role in the rejection of nonwords in a lexical decision task. This lends support for the existence of a GPC procedure in the generation of phonological codes.

Finally, before the activation and synthesis model can be accepted, it needs to provide an account of the reading displayed by surface dyslexic patients (Holmes, 1973; Marshall \& Newcombe, 1973). These patients are believed to have sustained damage to their directvisual lexical access pathway. Therefore, they have to rely on indirect phonological access (although this route may also show some impairment). Consequently, surface dyslexics have great difficulty reading irregular English words (Shallice \& Warrington, 1980) and significantly less difficulty reading regular ones. If it is the case that visual information from print cannot reach the lexicon, then lexical phonology cannot be accessed. In this case, it is hard to see how these patients can either gain access to the internal lexicon or name words without the assumption that a nonlexical phonological code is generated. If this phonological code then can be generated, it would seem unnecessary to presume that under normal circumstances this procedure is abandoned and a lexical activation and synthesis procedure is utilized instead.

\section{REFERENCES}

BARON, J. Mechanisms for pronouncing printed words: Use and acquisition. In D. LaBerge \& S. J. Samuels (Eds.), Basic processes in reading: Perception and comprehension. Hillsdale, N.J: Erlbaum, 1977. (a)
BAron, J. What we might know about orthographic rules. In S. Dornic (Ed.), Attention and performance VI. Hillsdale, N.J: Erlbaum, 1977. (b)

BAron, J. Orthographic and work-specific mechanisms in children's reading of words. Child Development, 1979, 50, 60-72.

Baron, J., \& Strawson, C. Use of orthographic and wordspecific knowledge in reading words aloud. Journal of Experimental Psychology, 1976, 2, 386-393.

Bauer, D. W., \& Stanovich, K. E. Lexical access and the spelling-to-sound regularity effect. Memory \& Cognition, 1980, 8, 424-432.

Colthe art, M. The internal lexicon and its access during reading. In J. P. Sutcliffe (Ed.), Conceptual analysis and method in psychology. Sydney: Sydney University Press, 1978.

Colthenat, M. Lexical access in simple reading tasks. In $\mathbf{G}$. Underwood (Ed.), Strategies of information processing. New York: Academic Press, 1979.

Coltheart, M., Besner, D., Jonasson, J., \& Daveuaar, E. Phonological encoding in the lexical decision task. Quarterly Journal of Experimental Psychology, 1979, 31, 489-507.

Colthenrt, M., Davelaar, E., Jonasson, J. T., \& Begner, D. Access to the internal lexicon. In S. Dornic (Ed.), Attention and performance VI. Hillsdale, N.j: Erlbaum, 1977.

GLUShкo, R. J. The organization and activation of orthographic knowledge in reading aloud. Journal of Experimental Psychology: Human Perception and Performance, 1979, 5, 674-691.

Govar, P. B., \& Cosky, M. J. One second of reading again. In N. J. Castellan, D. B. Pisoni, \& G, R. Potts (Eds.), Cognitive theory (Vol. 2). Hillsdale, N.J: Erlbaum, 1977.

Holmes, J. Dyslexia: A neurolinguistic study of traumatic and developmental disorders of reading. Unpublished doctoral dissertation, Edinburgh University, 1973.

Marcel, A. Surface dyslexia and beginning reading: A revised hypothesis of the pronunciation of print and its impairments. In M. Coltheart, K. Patterson, \& J. C. Marshall (Eds.), Deep dyslexia. London: Routledge \& Kegan Paul, 1980.

Marcel, A., \& Patterson, $K$. Word recognition and production: Reciprocity in clinical and normal studies. In J. Requin (Ed.), Attention and performance VII. Hillsdale, N.J: Erlbaum, 1978.

Marshall, J. C., \& Newcombe, F. Patterns of paralescia: A psycholinguistic approach. Journal of Psycholinguistic Research, 1973, 2, 175-195.

Midgley-West, L. Phonological encoding and subject strategies in skilled reading. Unpublished doctoral dissertation, University of London, Birkbeck College, 1979.

Morton, J., \& PAtte rson, K. A new attempt at an interpretation, or, an attempt at a new interpretation. In $\mathbf{M}$. Coltheart, $K$. Patterson, \& J. C. Marshall (Eds.), Deep dyslexia. London: Routledge \& Kegan Paul, 1980.

Rubenstein, H., Lewis, S. S., \& Rubenstein, M. A. Evidence for phonemic recoding in visual word recognition. Journal of Verbal Learning and Verbal Behavior, 1971, 10, 645-657.

Shallice, T., \& Warrington, E. K. Single and multiple component central dyslexic syndromes. In $M$. Coltheart, $K$. Patterson, \& J. C. Marshall (Eds.), Deep dyslexia. London: Routledge \& Kegan Paul, 1980.

Stanovich, K. E., \& Bauer, D. W. Experiments on the spellingto-sound regularity effect in word recognition. Memory \& Cognition, 1978, 6, 410-415.

VENEZKY, R. L. The structure of English orthography. The Hague: Mouton, 1970.

WiJk, A. Rules of pronunciation for the English language. London: Oxford University Press, 1966. 
Appendix 1

\begin{tabular}{|c|c|c|c|c|c|c|c|}
\hline \multirow{2}{*}{$\begin{array}{c}\begin{array}{c}\text { Pseudo- } \\
\text { homophones }\end{array} \\
\text { ILE }\end{array}$} & \multirow{2}{*}{$\begin{array}{c}\begin{array}{c}\text { Non- } \\
\text { words }\end{array} \\
\text { IFE }\end{array}$} & \multicolumn{2}{|c|}{ Words } & \multirow{2}{*}{$\begin{array}{c}\begin{array}{c}\text { Pseudo- } \\
\text { homophones }\end{array} \\
\text { RIE }\end{array}$} & \multirow{2}{*}{$\begin{array}{c}\begin{array}{c}\text { Non- } \\
\text { words }\end{array} \\
\text { KIE }\end{array}$} & \multicolumn{2}{|c|}{ Words } \\
\hline & & SAME & LUNCH & & & DRIP & TIDE \\
\hline BRUDE & TRUDE & FULL & BED & THROAN & PHROAN & STREET & WOOD \\
\hline CHUZE & THUZE & SEAT & THORN & WATE & WUTE & WINE & MEET \\
\hline GRONE & BRONE & BOLD & MINER & WOAR & WOAL & PRAY & FOOD \\
\hline HOAL & JOAL & LASH & ITCH & BORL & BARL & MILE & PINE \\
\hline MONE & MOBE & BELOW & TREE & BRAIK & PRAIK & BODY & FIELD \\
\hline PEEZE & JEEZE & CART & DREAM & FLOO & FROO & RING & KEEPER \\
\hline THROO & PHROD & WEAK & RAIN & BOALED & NOALED & HAND & FACE \\
\hline WAID & DAID & HARP & GIRL & BILD & FILD & SLOW & SPINE \\
\hline WURLD & MURLD & JOKE & GINGER & FRAZE & FRUZE & RARE & TRICK \\
\hline AHMS & AHNS & BEEF & BIRD & HELE & HEFE & BOOT & PRINT \\
\hline BOR & BOL & BLUE & TABLE & LEKE & DEBE & SUCK & GRASS \\
\hline CORT & LORT & CHAIR & NECK & PORZE & PORCE & STIFF & SKIRT \\
\hline BLOO & PLOO & SHOE & WORD & TAKS & KAKS & STEAL & LETTER \\
\hline BROOZE & DROOZE & THIEF & MINE & TODE & DODE & WITCH & FRESH \\
\hline KORD & KORP & GRADE & BARN & STAWK & STEEK & CHAT & APPLE \\
\hline HORL & DORL & CHURCH & CAVE & FLORE & FLURE & DRAG & WALK \\
\hline LAKS & GAKS & FAIL & SNOB & BIAR & JAIR & HEAT & HUNDRED \\
\hline WUN & VUN & SHEEP & FLOOD & GRAIT & BRAIT & GREEN & DRAGON \\
\hline
\end{tabular}

Appendix 2

Mean Reaction Times (in Milliseconds) and Standard Deviations

Obtained by the Words, Pseudohomophones, and Nonwords

\begin{tabular}{|c|c|c|c|c|c|c|}
\hline & \multicolumn{2}{|c|}{ Words } & \multicolumn{2}{|c|}{$\begin{array}{c}\text { Pseudo- } \\
\text { homophones }\end{array}$} & \multicolumn{2}{|c|}{ Nonwords } \\
\hline & Mean & $\mathrm{SD}$ & Mean & SD & Mean & SD \\
\hline Intact & 573 & 63 & 721 & 92 & 671 & 84 \\
\hline Disrupted & 612 & 72 & 710 & 89 & 708 & 87 \\
\hline
\end{tabular}

(Manuscript received August 22, 1980;

revision accepted for publication September 24, 1981.) 